\title{
Chronic Leg Ulcer Due to Arteriovenous Malformation: A Case Report
}

\author{
Mehmet Isik $^{1}$, Yalçın Günerhan ${ }^{1}$, Erdal Ege ${ }^{1}$
}

1) Necmettin Erbakan University, Meram Medicine Faculty, Department of Cardiovascular Surgery, Konya, Turkey.

\begin{abstract}
Backround: Peripheral arteriovenous malformations are rare clinical situations and the clinical spectrum varies from asymptomatic birth spot to life-threatining congestive heart failure. Also, venous compression and insufficiency result in stasis, dermatitis and ulcer development. Leg ulceration as a complication of arteriovenous malformation has been reported after tibial arteriovenous malformation causing venous congestion or femoral arteriovenous malformation resulting in a steal syndrome. Symptomatic and progressive growing arteriovenous malformations should be treated.

Case Report: In this study we present a successful surgical and medical treatment of a fifty-four year old female patient with chronic leg ulcer due to newly diagnosed arteriovenous malformation.

Conclusion: One of the important causes of chronic leg ulcer is delayed diagnoses like arteriovenous malformation so correct diagnoses and adequate treatment including surgery is important in patients with chronic leg ulcer due to arteriovenous malformation.
\end{abstract}

Keywords: Arteriovenous malformation, leg ulcer, surgery. 
Case

A 54-year-old female patient was admitted to our clinic with symptoms of irregularly shaped chronic leg ulcer located on the lateral and pretibial side of the lower right leg. Ulcer formation started five years ago and didn't respond to medical treatment and enlarged. She noted increasing warmth, pain and eruptions without complete healing for three years.

The patient had no history of diabetes mellitus, hypertension and trauma. Laboratory findings showed no abnormality except a mild elevation in CRP $(19,8$ $\mathrm{mg} / \mathrm{L}$ ). There were no signs of deep or superfifcial venous insufficiency in lower extremity venous doppler usg. Patient was taken to hybrid operation room. Arteriography to the right lower extremity revealed multipl arteriovenous malformations related with vena saphena magna in the lower leg.

Successful therapy consisted of ligature of multipl arteriovenous connections, excision of vena saphena magna, ulcer and necrotic tissues (Figüre 1-Figüre 2). In addition to surgery, bed rest and adequate medical treatment including antibiotic, topical agents and venotonic drugs, the ulcer healed leaving a shallow scar and pigmentation after five mounths.

\section{Discussion}

Chronic leg ulcers are the clinical conditions that disrupt the quality of life and need long-term treatment. The most common cause is chronic venous insufficiency, but a number of different clinical conditions may play a role in the etiology. One of the important and rare causes is the arteriovenous malformations. ${ }^{(3)}$

Direct connection of arteries or arterioles to the venous system without any capillary bed can be described as arteriovenous malformation and it can be occured sporadically or as a component of inherited vascular malformation syndromes. ${ }^{(4)}$ Arteriovenous malformations may exist for many years without symptoms. ${ }^{(5)}$ Symptoms of fistulas due to malformation differ from congestive heart failure to distal leg ischaemia result to ulcer formation. ${ }^{(6)}$

Chronic leg ulcers may be evaluated as the result of

Figure 1. Intraoperative view after a portion of arterial and venous connections of arterio-venous malformation are attached

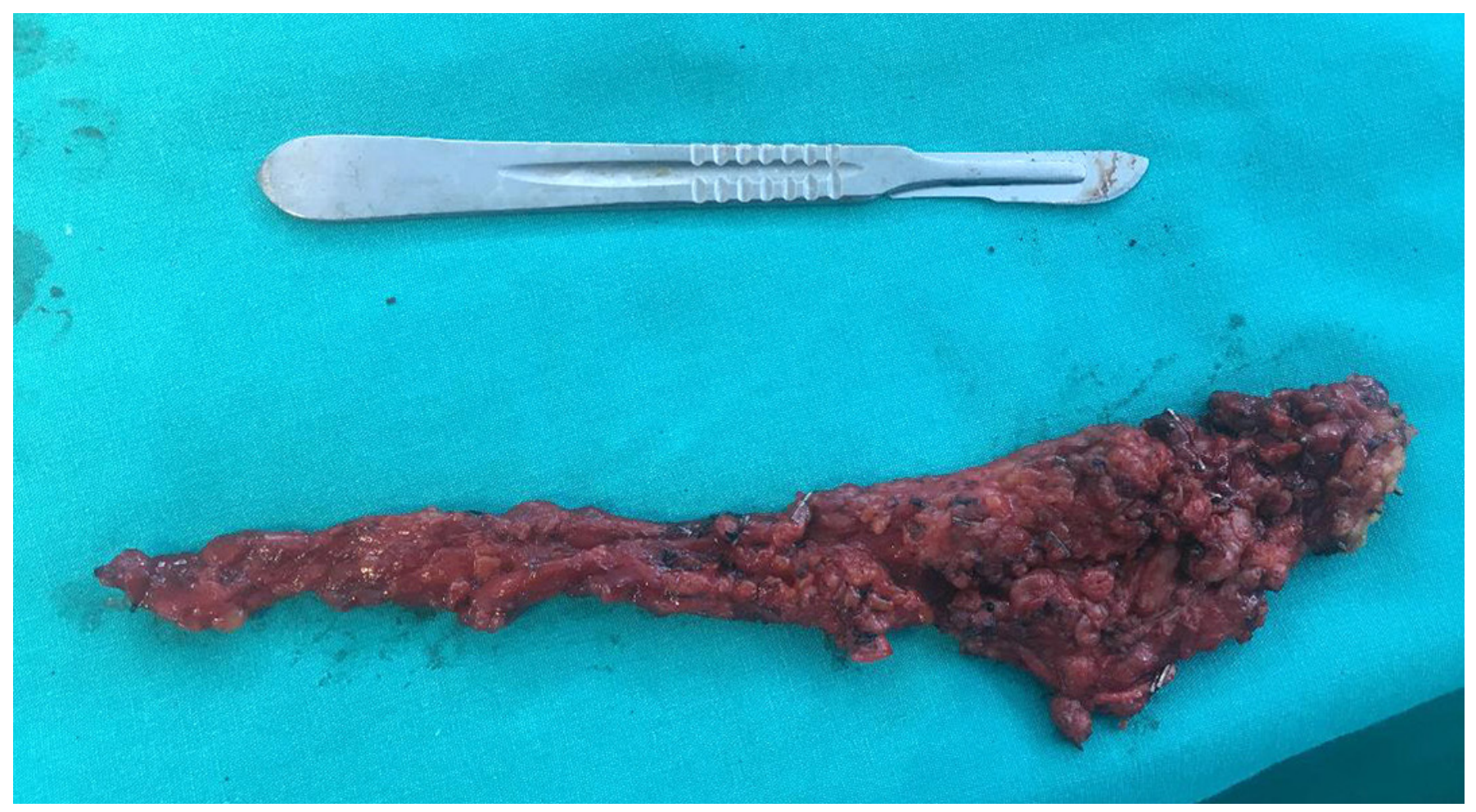


venous insufficiency in some patients for many years so treatment delays because of misdiagnosis. So accurate diagnoses and appropriate management is important because of long duration of asymptomatic period and serious symptoms that may occur. ${ }^{(7)}$

Patients with arteriovenous malformation that are symptomatic or have follow-up growth should be treated absolutely to avoid clinical complaints or prevent complications that may develop. ${ }^{(8)}$

As a conclusion, it should be kept in mind that arteriovenous malformation may be a cause of chronic leg ulcer. Correct diagnoses and adequate treatment including surgery is important in patients with chronic leg ulcer due to arteriovenous malformation.

Figure 2. Removed status of arterio-venous malformation after binding arterial and venous branches

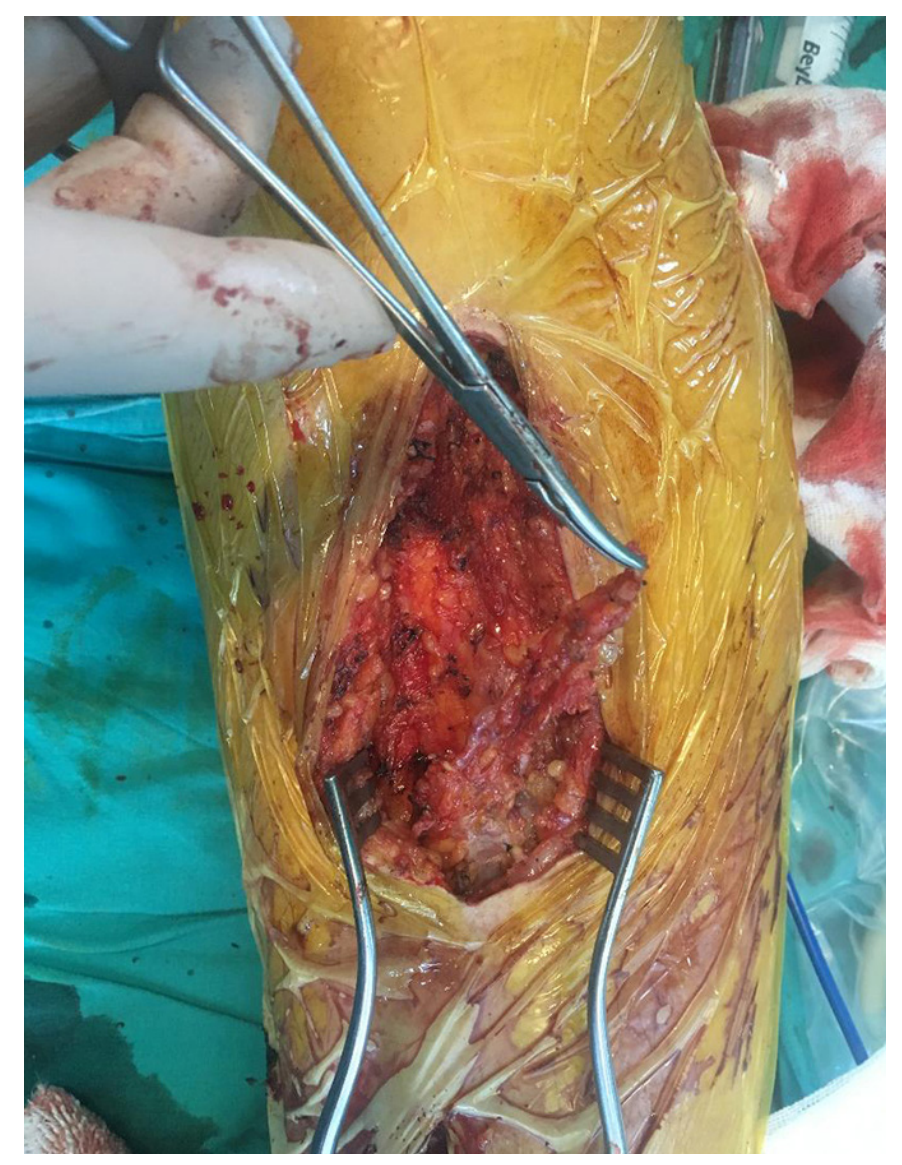




\section{References}

1. Garzon MC, Huang JT, Enjolras O, Frieden IJ. Vascular Malformations: Part I. J Am Acad Dermatol 2007; 56(3): 353-370.

2. Young JC, Dardik A, Sumpio B, Indes J, Muhs B, Chaar CIO. Venous Ulcer: Late Complication of a Traumatic Arteriovenous Fistula. Annals of Vascular Surgery 2015; 29(4): 836.

3. Dogra S, Sarangal R. Summary of recommendations for leg ulcers. Indian Dermatol Online J 2014; 5(3): 400-407.

4. Whitehead KJ, Smith MCP, Li DY. Arteriovenous Malformations and Other Vascular Malformation Syndromes. Cold Spring Harb Perspect Med 2013; 3(2): 6635-6644.
5. Bormann G, Preusser KP, Marsch WC. Arteriovenöse Fistel als seltene Ursache eines Ulcus cruris. Hautarzt 2002; 53: 735-738.

6. Suknaic S, Erdelez L, Skoplijanac A, Sef D, Novacic K. Chronic ischaemic leg ulcer as a late complication of post-traumatic arteriovenous fistula. Phlebology 2012; 27(3): 124-127.

7. Gupta S, Andersen C, Black J, de Leon J, Fife C, Lantis li JC et al. Management of Chronic Wounds: Diagnoses, Preparation, Treatment, and Follow-up. Wounds 2017; 29(9): 19-36.

8. Tanyeli Ö, Dereli Y, Altınbaş Ö, Çiçek MC, Görmüş N. Yüzük Şeklinde Digital Arteriovenöz Malformasyon: Olgu Sunumu. CausaPedia 2015; 4: 1084-1089.

Received: 19/04/2018

Accepted: 26/05/2018

Published: 05/06/2018

Disclosure and conflicts of interest:

The authors declare no conflict of interest.

Corresponding author:

Dr. Mehmet Isik

Mail:drmisik@hotmail.com 